\title{
Review
}

\section{The need for a multi-level drug targeting strategy to curb the COVID-19 pandemic}

\author{
George J. Kontoghiorghes ${ }^{1, *}$, Stella Fetta ${ }^{1}$, Christina N. Kontoghiorghe ${ }^{1}$ \\ ${ }^{1}$ Postgraduate Research Institute of Science, Technology, Environment and Medicine, 3021 Limassol, Cyprus
}

\section{TABLE OF CONTENTS}

\author{
1. Abstract \\ 2. Introduction \\ 3. The effects of vaccines on the COVID-19 pandemic \\ 4. Drug based concepts for the prevention of COVID-19 \\ 4.1 Factors contributing to variable susceptibility to SARS-CoV-2 infection \\ 4.2 Drug based examples of prevention targets against COVID-19 infection \\ 5. Drug targeting based theory and methods against SARS-CoV-2 \\ 6. Examples of drugs that are widely used in COVID-19 patients \\ 7. Examples of drugs that could be used in COVID-19 \\ 8. Pharmacological and toxicological aspects of drugs against COVID-19 \\ 9. New developments affecting multi-level drug targeting strategies against COVID-19 \\ 10. Conclusions \\ 11. Author contributions \\ 12. Ethics approval and consent to participate \\ 13. Acknowledgment \\ 14. Funding \\ 15. Conflict of interest \\ 16. References
}

\section{Abstract}

Thousands of drugs, nutraceuticals and their combinations can be used to select candidate therapeutics for targeting SARS-CoV-2 and its symptoms in order to curb COVID-19. A comprehensive, multi-level strategy against COVID-19 should include drug targeting of biomolecules and biochemical pathways involved in the prevention and proliferation of the infection, and the fatal or serious symptoms following infection. Several drugs are routinely used in the treatment of different categories of seriously ill COVID-19 patients including tocilizumab, remdesivir and dexamethasone. The current risk/benefit assessment supports the emergency testing and approval of more drugs. The process for new drug selection could be based on the identification of one drug for one target, or of a multi-potent drug for many targets and drug combinations for one or more targets, that can cause a substantial reduction in the high mortality rate of COVID-19. Several drugs have been identified that can fit this potential role by targeting different stages of COVID-19 including baricitinib, molnupi- ravir and PF-07321332/ritonavir and also the combination of deferiprone with $\mathrm{N}$-acetylcysteine for inhibiting the vicious circle of oxidative stress toxicity and endothelial cell damage. Most of these drugs are expected to be effective against all the SARS-CoV-2 variants including Omicron (B.1.1.529) and also the associated COVID-19 complications.

\section{Introduction}

Coronavirus disease 2019 (COVID-19) is an infection caused by the severe acute respiratory syndrome coronavirus 2 (SARS-CoV-2), which affects mainly the respiratory but also the cardiovascular, gastrointestinal, nervous, immune, and hematopoietic systems. The design of strategies related to targeted drug therapies against COVID19 , could encompass all aspects of the viral disease process and its effects, as well as the associated concomitant underlying conditions of infected patients. Targeted therapeutic strategies could include molecular aspects of transmission, host infiltration, proliferation and vital organ protec- 
tion from the toxic effects of SARS-CoV-2. Drug combinations with vaccines enhancing the efficacy of antiviral activity against SARS-CoV-2 may also be considered as therapeutic options.

The risk/benefit assessment for the introduction of new drug targeted treatment strategies, one year following the COVID-19 pandemic is urgent, considering that the present rate of mortality of COVID-19 patients worldwide is still very high [1]. Furthermore, emergency drug treatments are required for several other reasons including the continuous emergence of new, more toxic variants of SARS-CoV-2, the high rates of morbidity and mortality due to other unrelated diseases worldwide and especially in developing countries due to overstretched of the healthcare systems. In addition to the emergence of resistant strains of the virus, of major concern is the occurrence of reinfection in previously infected or vaccinated persons, particularly in countries with a high vaccination rate.

One year following the announcement from the World Health Organization (WHO) of the COVID-19 pandemic, it is estimated that as of the end of March 2021, with a world population of 7.8 billion, about 130 million people have been infected with SARS-CoV-2, 105 million have recovered or been discharged, 2.8 million have died and 22.5 million were active cases. The number of infected people has exceeded 187 million including 4 million deaths and the number of vaccinated people has risen to 3.4 billion by the middle of July 2021 [1].

The annual rate of mortality in COVID-19 is much higher in comparison to the seasonal influenza viral infection estimated at 0.65 million and also to malaria, where the annual rate is 0.41 million of which 265,000 are children in developing countries [2-4]. The major symptoms and cause of mortality in COVID-19 are associated with a respiratory syndrome and lung damage caused by a state of hyper-inflammation, the 'cytokine storm', which involves granulocyte-macrophage colony-stimulating factor (GMCSF) activation, increase in cytokines, e.g., IL-1, IL6, IL8 and other inflammatory markers, e.g., C-reactive protein, D-dimer and serum ferritin. The respiratory syndrome causes progressive deterioration of the respiratory system and inability to breathe normally. It is characterized by different stages of regression from fever to hypotension, coagulopathy, respiratory failure, hypoxia and death [5-7].

New, conventional and unconventional approaches including new prevention and treatment options are needed in addition to vaccines to curb the high morbidity and mortality rates, which have been observed worldwide as a result of the COVID-19 pandemic. The current general therapeutic strategies are based on national initiatives for vaccination of the population, the reduction of the viral load and also of the transmission of SARS-CoV-2, as well as the reduction or elimination of the fatal and other serious toxic side effects of the infection. In this context, concerted efforts and re-appraisal of the risk/benefit assessment for the prevention and treatment options should include targeting methods for the inhibition of proliferation of SARS-CoV-2 worldwide and for the prevention/reduction of fatal pulmonary and other organ damage in symptomatic patients.

The current vaccine treatment strategy, its combination with reduced contact/distancing and vigilant personal hygiene appear to be effective policies in reducing the mortality and morbidity rate in a few countries but not worldwide [1, 3]. However, the limited success of the current health policies on COVID-19 has been associated with a worldwide economic decline and increases in morbidity and mortality from other diseases, especially in developing countries (Fig. 1).

\section{The effects of vaccines on the COVID-19 pandemic}

It is estimated that there are about 100 COVID-19 vaccines at various stages of clinical development and use, involving companies mainly in the USA, EU, UK, Russia and China, and also smaller countries such as Cuba [6, 8, 9]. There is no worldwide policy or consensus on the selection of vaccines and all efforts are mostly based on national initiatives and the private industry.

Many variations and factors apply in the selection and use of vaccines in each country, in addition to the efficacy and safety parameters. These include costs, availability, storage facilities, national rivalries, commercial considerations etc. Similarly, there are many parameters for comparing the efficacy of vaccines, which can be based on various outcomes in COVID-19 patients such as the rate of mortality, severe disease and hospitalization, re-infection, transmission potential, as well as a combination of these outcomes. For example, in a recent comparison of various vaccines considering their efficacy and effectiveness based on studies measuring the prevention of mild to moderate COVID-19 infection, the estimated relative risk reduction of attack rates with and without a vaccine suggested that for BNT162b2 mRNA (Pfizer-BioNTech) was 95\%, for mRNA-1273 (Moderna-USA, NIH) was 94\%, for Gamaleya GamCovidVac (Sputnik V) was 90\% and for ChAdOx1 nCov-19 (AstraZeneca-Oxford) was 67\% [9].

International debates and controversies on the risk/benefit assessment of vaccines are currently in progress mainly driven by commercial considerations. In general, all approved vaccines against SARS-CoV-2 appear to be effective, with negligible toxicity in the short term, despite reports of a few cases of thromboembolism and myocardial inflammation following millions of vaccinations [9, 10]. However, as a result of emergency and rapid approvals by the regulatory authorities there is no information available for the possible long term toxic side effects of the different vaccines, which is a prerequisite for the usual drug development route [11]. 


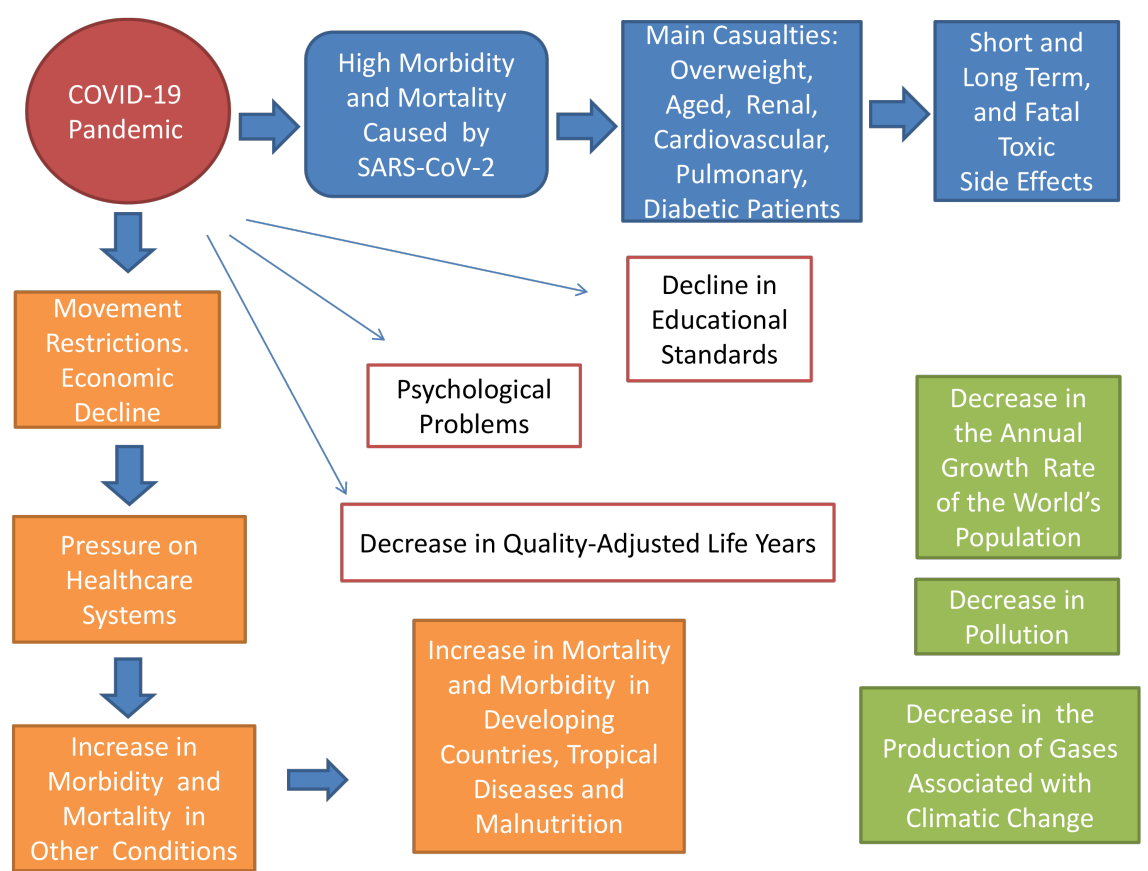

Fig. 1. The general effects of the COVID-19 pandemic. High rate of mortality is mainly observed in the aged population and different categories of patients. There are many, negative implications in almost all human activities and changes in daily life style as a result of movement restrictions, which have been imposed for controlling the disease.

Although it is estimated that protection in general from serious illness in relation to SARS-CoV-2 infection, 2-3 weeks following vaccination, is about $65 \%$ following the first dose and 67-95\% in fully vaccinated individuals, there are no available data for the duration of protection following vaccination, which is currently estimated at minimum 3 months. Similarly, the efficacy of the various vaccines against the different SARS-CoV-2 variants of concern, e.g., the UK (B117 or alpha), South African (B1351 or beta), Brazilian (P1 or gamma) and Indian (B16172 or delta) variants appears to be different and for example only $40 \%$ estimated efficacy against the South African variant [12-16]. It also appears that the level of antibody production against SARS-CoV-2 is variable amongst vaccinated individuals including different patient groups, e.g., obese, smokers, hypertension, chronic lymphocytic leukemia and myeloma patients, where in the latter two groups low level of antibody production and higher risks of mortality have been reported $[17,18]$. Similar reduction in antibody production has been observed in vaccinated patients of inflammatory conditions treated with methotrexate [19].

In general variable levels of antibody production are observed in SARS-CoV-2 infected individuals with or without underlying conditions, where susceptibility to reinfection and different rates in morbidity of about $72 \%$ and mortality of less than $1 \%$ may also in general be observed [20-23]. Most frequent side effects persisting 1-2 months following the SARS-CoV-2 infection include neurological changes, shortness of breath or dyspnea, fatigue or exhaustion and sleep disorders or insomnia [22-25]. However, overall it appears that vaccinated individuals have in general lower chances of infection, developing serious symptoms from the infection and transmitting SARS-CoV-2 to others.

In addition to the economic and health system deterioration worldwide, there are many other adverse effects which may limit the success of the present operated policies for curbing the COVID-19 pandemic (Fig. 1) [26]. The limitations of the present policies include the low availability of vaccines in many countries and also the need for new vaccines to control the emergence of new SARS-CoV2 mutations and variants, as well as suspected more virulent variants in the future, which appear to originate from countries with lower rates of vaccination. Other side effects of the prolonged enclosures are the psychological, educational, socioeconomic implications (Fig. 1) [25-29].

Under the present circumstances, new approaches, concepts and worldwide concerted efforts are urgently needed to be tested and introduced on all aspects of the COVID-19 pandemic control, including emergency drug based prevention, proliferation and treatment methods against SARS-CoV-2.

\section{Drug based concepts for the prevention of COVID-19}

As Hippocrates suggested more than 2000 years ago, prevention is better than cure in any disease. Accordingly, reducing the surrounding viral load and preventing 
nasopharyngeal viral entry from flying droplets originating from the exhalation of infected SARS-CoV-2 individuals could reduce in most cases the transmission of the infection. Transmission is mostly carried out in enclosed areas and usually implicates asymptomatic infection carriers within families, the workplace, schools and social gatherings [30, 31].

\subsection{Factors contributing to variable susceptibility to} SARS-CoV-2 infection

The susceptibility and response to SARS-CoV-2 of infected individuals is variable and depend on many factors including viral load contamination, health status, age, gender, climate, underlying diseases, environmental, life-style, nutrition, immunological and genotypic aspects, treatment with medicinal drugs etc. [20, 32-45]. Similarly, although immunization with vaccines against SARS-CoV-2 appears to offer effective protection for the vast majority of vaccinated individuals, innate immunity and immune function is critical for controlling viral and other infections for non-responders to vaccines or unvaccinated individuals.

In general, immune function inherently declines with age, leading to reduced immune response, increased susceptibility to infections and also chronic inflammation, with cancer, respiratory, neurodegenerative and other diseases occurring more frequently in old age [34, 46, 47]. In this context, aged individuals appear to be more susceptible to SARS-CoV-2 infection with increased rates of mortality than younger individuals [34, 38]. Other susceptible groups to SARS-CoV-2 infection with increased rates of morbidity and mortality include overweight, cardiovascular, pulmonary, renal, diabetic, immuno-compromised and other patients with co-morbidities (Fig. 1) [6, 48-51]. Variable susceptibility and response to SARS-CoV-2 infection, as well as variability in the rate of morbidity and mortality is observed in other categories of infected patients including pregnant women and newborns [52].

The enhancement of innate immunity by adopting healthy nutritional and other habits such as the Mediterranean diet, taking vitamin C (e.g., $200 \mathrm{mg}$ twice daily) and vitamin D (e.g., $400 \mathrm{IU}-10 \mu \mathrm{g} /$ day), consuming other essential nutrients and metal ions such as zinc that boost immunity, living in a clean environment, exercise, and also preventing concomitant infections, reducing stress, smoking cessation, weight loss, etc. could reduce susceptibility and associated complications due to SARS-CoV-2 infection [45-47, 53-57].

4.2 Drug based examples of prevention targets against COVID-19 infection

New prevention policies and measures could be introduced to reduce COVID-19, which for example may involve thorough educational campaigns on all aspects of the viral infection and more sophisticated options including face masks and antiviral cleaning procedures [58]. For example, the daily use of a simple prototype two layer mask containing a disposable alcohol cotton gauze between the two layers, an alcohol mouth wash and anti-viral nasal spray could decrease viral load body entry, contamination of bystander individuals and in general the transmission of the infection (Fig. 2). It should be noted that the inhalation of small amounts of alcohol are non-toxic and the antiviral and anti-microbial properties of externally used alcohol is widely known [59-61]. Variations of this prototype face mask may include anti-viral drugs and or ethereal oils dissolved in alcohol disposable cotton gauze for wider acceptability and applications, especially if the associated expenses are covered or subsidized by governments or international organizations. The expenditure of such masks is negligible in comparison to testing kits/procedures for SARS-CoV-2 or the treatments currently adopted for COVID-19.

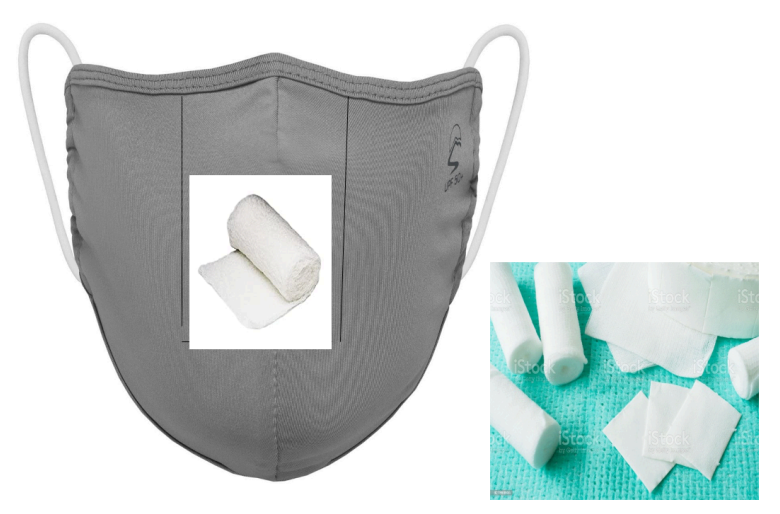

Fig. 2. Example of a prototype face mask for the prevention of SARSCoV-2 transmission. An ordinary face mask with a pocket covering the mouth and nose area is shown, where a disposable cotton patch ("filter") containing alcohol is inserted. Alcohol can disinfect the virus and other microbes present in exhaled droplets of infected individuals and prevent transmission.

Further preventative measures against SARSCoV-2 include the inhibition or prevention of increased viral load exposure of the lungs, which is the major target organ associated with severe acute respiratory syndrome, increased lung damage and mortality in COVID-19 [36, 62, 63]. In this context, antiviral targeting of the lungs requires several strategies including regular antiviral drug preventative treatment of the nasopharyngeal entry through the larynx, trachea, bronchi and of the lungs [64, 65]. The vast experience in the use of inhalers and nebulizers for drug delivery directly through the respiratory route to the lungs has not been fully investigated for the drug prevention and treatment of COVID-19 [66-70]. This topical method of drug delivery to the lungs could be substantially more effective and less toxic than systemic drug delivery. Similarly, alcohol based mouthwash and nasal antiviral drug delivery could also be used for reducing or preventing SARS-CoV-2 viral entry and associated viral load [64-66]. 


\section{Drug targeting based theory and methods against SARS-CoV-2}

There are many biochemical and other pathways which can be targeted by drugs in order to reduce the growth and proliferation of SARS-CoV-2, as well as the symptoms associated with the cellular and tissue damage causing the fatal and other serious toxic side effects observed in COVID-19. In this context, there are more than 50,000 registered drugs and thousands of nutraceuticals that can be used in order to select candidate therapeutics against COVID-19. Hundreds of such drugs and nutraceuticals and more investigational new drugs (IND) have already been proposed in the medical literature for targeting specific pathways against COVID-19, but only a few have been tested in clinical trials $[6,8,11,55,65,71,72]$.

Despite that the mechanism of growth, proliferation and toxic action of SARS-CoV-2, as well as its side effects have been evaluated and characterized, there has not been a systematic evaluation of potential drug therapeutics to reverse the SARS-CoV-2 toxicity $[6,8,73,74]$. In this context, the evaluation process of new drug selection could be designed based on the identification of one drug for one target, of a multi-potent drug for many targets and drug combinations for one or more targets. Priority targeting could be the selection of any drug (s) candidates that can significantly reduce the current rate of mortality to minimum acceptable levels, e.g., similar to the influenza virus. This goal may be achievable and also preferable and with lower risk in the long term in comparison to the treatments offered by renewable vaccines for toxic variants of SARS-CoV-2. Combination therapies with vaccines may also achieve this goal, especially if COVID-19 cannot be controlled and the pandemic continues for years to come.

There are several other target stages of COVID-19 in addition to prevention discussed above, where targeted drug treatment intervention could reduce the present rate of COVID-19 associated mortality. One line of drug targeting could involve several steps related to viral growth and proliferation including direct action on the virus, inhibition of viral attachment to host cells, inhibition of viral growth and proliferation in the host cell and inhibition of viral exit from the host cell (Table 1) [6, 8, 73-76]. In this context, all aspects of the viral life cycle should be considered as potential targets for anti SARS-CoV-2 activity.

A different line of drug targeting strategy is in relation to the fatal and other serious toxic side effects of COVID-19. In this case, drug targeting could involve the reduction of immune system hyper-activation and hyperinflammation caused by the 'cytokine storm', inhibition or reduction of endothelial damage, inhibition of tissue damage caused by oxidative stress toxicity, inhibition/reduction of the acute respiratory distress syndrome (ARDS), prevention of hypoxia and inhibition/reduction of multi-organ and systemic failure. Similar steps could be taken for the selec- tion of drugs for the prevention of coagulopathy and sepsis, which are also contributory factors related to the high mortality rates observed in COVID-19 (Table 1) [74, 77, 78].

Another line of drug targeting strategy may involve pathways associated with abnormal haematological, biochemical and other changes recorded during the different stages of COVID-19 and in particular those associated with increased mortality, where the connection with the pathological picture has not yet been fully evaluated or clarified. In this context, drug targeting involving the etiology of abnormal changes in one or more parameters including the high level of IL-6, C-reactive protein, lactate dehydrogenase (LDH), serum ferritin, D-dimer, myoglobin, rhabdomyolysis, neutrophil count, and neutrophil/lymphocyte ratio, as well as low level albumin, serum iron, lymphocyte count, monocyte count, and ratio of peripheral blood oxygen saturation to fraction of inspired oxygen (SpO2/FiO2) may reduce mortality (Table 1) [79-83].

Many more drug targeting options are associated specific proteins, protein receptors, mRNA, specific biochemical pathways and cells, e.g., macrophages and platelets, which may play a critical role in the proliferation of SARS-CoV-2, as well as the outcome of the COVID-19 infection [69, 84, 85]. Furthermore, drug targeting strategies may involve the activity of proteomic, genomic, transcription and other factors associated with the mRNA and proteins of the virus and host cell (Table 1) [86-93].

Hundreds of registered candidate drugs and nutraceuticals can fulfill many of the characteristics of specific drug action for targets that are described in Table 1, as well as suitability for other targets of associated biochemi$\mathrm{cal} /$ physiological pathways against COVID-19. The selection of such candidate drugs are based on a risk/benefit assessment. However, despite the successes of vaccination the present high mortality rate in COVID-19 patients still justifies the speedy development of more such drugs against this disease.

\section{Examples of drugs that are widely used in COVID-19 patients}

There are several drugs which are routinely used in other diseases that have been approved and recommended by different regulatory authorities such as the European Medicines Agency (EMA) of EU, the Food and Drug Administration (FDA) of USA and WHO for use in COVID-19 patients. The drugs approved have been shown in randomized clinical trials to decrease the mortality rate in certain categories of COVID-19 patients. Specific protocols apply in the use of such drugs, e.g., dexamethasone, remdesivir and tocilizumab, including protocols for categories of COVID-19 patients according to the stage of the disease and symptoms and also in relation to other underlying conditions [8, 72, 74]. Similarly, several other known drugs such 
Table 1. Examples of major targets and their characteristics for new drugs designed against COVID-19.

Target Biomolecule, pathway or symptom

(a) Direct drug action against viral components, e.g., SARS-CoV-2 viral mRNA and spike (S) protein modification

The growth and proliferation of SARS-CoV-2

(b) Inhibition of SARS-CoV-2 viral attachment to host cell, e.g., drug interference and inhibition of viral S-protein attachment on host ACE2 and other receptors or enzymes, e.g., TMPRSS2

(c) Inhibition of viral growth and proliferation in the host cell, e.g., drugs increasing the $\mathrm{pH}$ in lysosome and drugs decreasing the rate of mRNA production

(d) Inhibition of viral exit from the host cell, e.g., drugs interfering with the release of new viruses from endosomes and cell membrane

(e) Prevention of coagulopathy, e.g., anti-coagulants

(f) Inhibition/reduction of immune system hyperactivation/hyper inflammation/‘cytokine storm' and participating components, e.g., drug regulating or modifying immune response hy-

The fatal and other toxic side effects of COVID-19 peractivation, anti-inflammatories; monoclonal antibodies against participating components such as GM-CSF and IL-6 or their receptors

(g) Inhibition/reduction of endothelial damage, e.g., drugs protecting primarily the endothelium of the lungs but also the heart and other affected organs

(h) Inhibition of tissue damage caused by oxidative stress toxicity, e.g., antioxidant drugs

(i) Inhibition/reduction of severe acute respiratory syndrome or ARDS

(j) Prevention of hypoxia, e.g., oxygen supply - ventilators; artificial haemoglobins

(k) Prevention of sepsis, e.g., antibacterial and other antimicrobial drugs

(l) Inhibition/reduction of multi-organ and systemic failure, e.g., drug combinations for salvaging different organs/systems

Pathways associated with biochemical changes in

(1) Target pathways leading to increases in parameters of symptomatic patients with COVID-

COVID-19

(a) IL-6, (b) C-reactive protein, (c) D-dimer, (d) serum ferritin, (e) lactate dehydrogenase (LDH), (f) myoglobin (rhabdomyolysis), (g) neutrophil count, (h) neutrophil/lymphocyte ratio, e.g., introduction of drugs interfering with metabolic pathways that can restore the increased parameters in associated biochemical molecules, cells or their function

(2) Target pathways leading to decreases in parameters of symptomatic patients with COVID19:

(a) low albumin level, (b) serum iron level, (c) lymphocyte count, (d) monocyte count, (e) ratio of peripheral blood oxygen saturation to fraction of inspired oxygen (SpO2/FiO2), e.g., introduction of drugs interfering with metabolic pathways that can restore the decreased parameters in associated biochemical molecules, cells or their function

\begin{tabular}{ll}
$\begin{array}{l}\text { Key biochemical molecules and pathways, cells, } \\
\text { systems and conditions playing a critical role in fa- } \\
\text { tal outcomes in COVID-19 }\end{array}$ & $\begin{array}{l}\text { Drug modulation of: (a) specific proteins, protein receptors, nucleic acid synthesis, (b) specific } \\
\text { biochemical pathways, e.g., mRNA production, (c) the activity of cells involved in critical } \\
\text { pathways, e.g., macrophages and platelets, (d) proteomic, genomic, transcription and other } \\
\text { factors associated with the mRNA and proteins of the virus and host cell }\end{array}$ \\
\hline \begin{tabular}{l} 
Co-morbidities related to fatal outcomes in $\begin{array}{l}\text { Prophylactic and other drug therapy for groups with increased susceptibility to COVID-19, } \\
\text { e.g., pulmonary, cardiovascular, diabetic, immune-compromised, transplanted, haematologi- } \\
\text { cal, oncological, obese and aged patients }\end{array}$ \\
\hline
\end{tabular}
\end{tabular}

as enoxaparin sodium, omeprazole, colchicine, and paracetamol are routinely used for different categories of patients with specific symptomatology in COVID-19.

The pharmacological activity and targets of each of the routinely used drugs in COVID-19 patients are different. In this context, the general mode of action of dexamethasone and other corticosteroids is the inhibition of the immune system including cytokine response. Clinical studies with dexamethasone have shown reduction in the rate of mortality by maximum one third, only in hypoxic COVID-19 patients who require supplemental oxygen or are on ventilators [94, 95]. Tocilizumab is a monoclonal antibody/interleukin-6 (IL-6) receptor antagonist approved in the treatment of refractory rheumatoid arthritis. Interleukin-6 appears to play a key role in the cytokine storm and hyper-inflammation in COVID-19 patients [9698]. Clinical studies with tocilizumab have shown reduction in the rate of mortality of hypoxic COVID-19 pa- 
tients with severe symptoms and lung involvement [97, 98]. Remdesivir is an antiviral drug with broad spectrum antiviral activity and initially used against hepatitis $C$ virus. It is a pro-drug, which is metabolized to a ribonucleotide analogue, inhibitor of viral RNA polymerase. In clinical studies remdesivir has been shown to cause a reduction in the rate of mortality of hypoxic COVID-19 patients [99-101].

In a typical protocol in a COVID-19 hospital clinic all patients receive anticoagulation therapy for thromboprophylaxis using low molecular weight heparin (LMWH), e.g., enoxaparin sodium (40-80 mg/day, sc) and some proton-pump inhibitors, e.g., omeprazole (40 mg/day, iv) for gastroprotection. Similarly, patients with fever or pain are treated using paracetamol ( 1 g to maximum $4 \times 1$ g/day, p.o. or iv) and patients with cardiac damage or myocarditis are treated using the lipophilic drug colchicine $(2 \times 0.5$ mg/day, p.o.) [102, 103].

Similar protocols have been introduced for dexamethasone and other corticosteroids, remdesivir and tocilizumab, which are also routinely used in COVID-19 patients. In particular dexamethasone (6 mg /day, p.o. or iv for 10 days) is used selectively only for hypoxic COVID19 patients. Similarly, remdesivir (200 mg, iv the first day, $100 \mathrm{mg}$, iv in subsequent days for up to 10 days) is recommended for hypoxic COVID-19 patients with pneumonia. Tocilizumab ( $8 \mathrm{mg} / \mathrm{kg}$, maximum dose $800 \mathrm{mg}$, iv; repeated within 12-48 hours if there is no response) is recommended near the beginning of the onset of the hyper-inflammation/'cytokine storm' under certain criteria including hypoxic patients with difficulties in breathing and also serum ferritin $>1000 \mathrm{ng} / \mathrm{mL}$ [94-101].

\section{Examples of drugs that could be used in COVID-19}

While major emphasis on curbing the COVID-19 pandemic has so far been given to vaccination, increasing number of drugs are regularly used and other are developed for targeting different aspects of the disease as shown in the target for COVID-19 examples of Table 1. In this context, hundreds of drugs have been proposed, some have been tested and few have reached phase III of clinical development.

The development of monoclonal antibodies for proteins and receptors involved in COVID-19, similar to tocilizumab is progressing. For example, lenzilumab has been shown in phase III studies to improve survival in hospitalized, hypoxic patients with COVID-19 pneumonia. The level of survival using lenzilumab was higher in comparison to the treatment with remdesivir and/or corticosteroids. Lenzilumab is a GM-CSF monoclonal antibody that directly binds GM-CSF and prevents signaling through its receptor [104]. Sotrovimab is another monoclonal antibody recently considered for approval by EMA for use in patients with COVID-19. The mode of action of sotrovimab is the inhibition of entry of SARS-CoV-2 into host cells, which is achieved through the attachment of the antibody to the spike (S) protein of SARS-CoV-2 [105].

Drug development in relation to some of the critical pathways and targets associated with the increased rate of mortality in patients with COVID-19, have not so far succeeded, e.g., chloroquine and hydroxychloroquine, whereas other drugs have not received sufficient attention [8, 75]. In particular, drug targeting and reversal of endothelial damage and also of tissue damage in the lungs and other organs due to a vicious circle of oxidative stress toxicity may prove beneficial for COVID-19 patients [106, 107]. Phase III studies with the antioxidant drug $N$-acetylcysteine (NAC), which increases intracellular glutathione levels were recently announced in COVID-19 patients in Iran [108]. However, previous clinical studies using NAC in ARDS patients have not shown satisfactory results [109, 110]. Combination of NAC with the other potent antioxidant drug deferiprone, which has different mechanism of antioxidant activity and also different targets related to oxidative stress toxicity, appears to offer better and more effective antioxidant therapeutic options [111, 112]. Furthermore, endothelial cell protection has been shown in clinical and nonclinical studies using deferiprone [113-116]. The prospects of further development of deferiprone for multi-potent activity against COVID-19, is also considered because of its antiviral properties [117].

\section{Pharmacological and toxicological aspects of drugs against COVID-19}

The relatively short life cycle of SARS-CoV-2 and associated toxicity suggests that proposed therapeutic drugs against COVID-19 should exert their therapeutic activity for reducing mortality in a matter of a few days or weeks rather than months. The risk/benefit assessment for this short therapeutic time window can generally allow the administration of repeated high doses of drugs at the maximum dose of the approved range. This short term treatment period also allows for the rapid approval of drug trials due to the emergency pandemic conditions [11].

The prospect of the development of effective drugs for each of the different stages of COVID-19 is also challenging, considering that prevention and early intervention in the infection could generally reduce the viral load, the prospects of developing serious illness and also the rate of mortality.

The selection and identification of a single drug that can limit the proliferation of SARS-CoV-2 or reduce substantially the rate of mortality in COVID-19 could ideally solve all the problems associated with the pandemic (Fig. 1). In most cases drug combination strategies may offer better therapeutic solutions. The same applies to different vaccine combinations. However, the prospect of drugdrug interactions or drug/vaccine interactions may limit the 
efficacy and increase the toxicity prospects of such combinations [118-120]. Most COVID-19 patients have other comorbidities and take medication for their treatment which can interact with the drugs used in the treatment of COVID19 and have an effect on their outcomes [118-120]. Similar interactions have been shown in the use of immunological and other drugs in combination with vaccines. For example infliximab, a monoclonal antibody used in rheumatoid arthritis and inflammatory bowel disease has been shown to attenuate the immunogenicity of BNT162b2 and ChAdOx1 nCoV-19 SARS-CoV-2 vaccines [121].

The wide use and rapid approval of monoclonal antibodies in clinical trials or for the treatment COVID-19 patients is indicative of the medical emergency due to the pandemic. It appears that similar to the vaccines against SARS-CoV-2, no long term toxicity testing was required for the initial approval of the use of monoclonal antibodies in refractory autoimmune diseases such as rheumatoid arthritis and inflammatory bowel disease. These emergency decision approvals question the motives of the regulatory authorities, considering that monoclonal antibody therapy and other drugs are very expensive and that inexpensive drugs like chloroquine and hydroxychloroquine widely used in malaria patients worldwide for many years are not developed or recommended for specific groups of COVID-19 patients because of short term toxicity in a cohort of patients $[6,11,122]$.

Considering the emergency situation, the general strategy for drug selection for various targets to curb the COVID-19 pandemic could be based on different methods involving the rapid testing and approval of medicines as previously shown in other drug development cases, including orphan drugs for diseases with no available treatments [11, 123-125]. Similar rapid testing and approval applies to widely used nutraceuticals, which mostly are plant products and food components, which can be used in many cases at high doses or in combinations [11, 123, 126]. Further considerations for drug selection and application for treating COVID-19 could also be based on personalized medicine parameters including absorption, distribution, metabolism, elimination, toxicity (ADMET) characteristics in each patient, drug interaction effects especially for drugs taken concurrently by COVID-19 patients with co-morbidities, which may have variable effects against SARS-CoV-2 or COVID-19. Similar drug interaction effects are envisaged in relation to vaccine responses [54, 123, 127].

Different aspects of the pharmacological and toxicological interactions of drugs should also be considered in relation to many other complex factors and sectors, which are continuously identified in relation to the progress of COVID-19 including molecular, multi-genomic and other effects, as well as other methods for trying to curb the COVID-19 [128-132].

\section{New developments affecting multi-level drug targeting strategies against COVID-19}

The COVID 19 pandemic is rapidly changing and developing in ways which affect daily life for people all over the world and the need for new therapeutic approaches, including the need for multi-level drug targeting strategies [123, 133, 134]. Despite the initial high expectations that COVID-19 could be contained similar to the epidemics of severe acute respiratory syndrome coronavirus 1 (SARSCoV-1) and the Middle East Respiratory Syndrome coronavirus (MERS-CoV) using prevention measures and also vaccination programs, there is increasingly new evidence that the COVID-19 pandemic is far from over [123, 135]. As of the end of October 2021 and while facing the fourth wave of the COVID-19 pandemic in European and other countries, the rate of infection and associated mortality has not been significantly reduced and more than 5 million people have already died worldwide. Similarly, despite that the worldwide vaccination program has progressed particularly in western countries, it still remains inadequate for other parts of the world, and as an example, only about $5 \%$ of the population of Africa is estimated to be vaccinated [1].

In addition to the increasing fatalities, new adverse developments regarding different categories of COVID-19 patients have been reported. These include re-infection of previously infected and also of vaccinated individuals, long term side effects including fatal acute respiratory syndrome in COVID-19 patients who no longer carry the virus, variations in response to vaccines and drugs by different categories of COVID-19 patients with various underlying diseases, the need for booster vaccinations in vaccinated individuals etc., all of which require further evaluation and new therapeutic approach strategies [136-138].

As the identification of new targets and proposed therapeutics for different categories of COVID-19 patients is continuously increasing, so the multi-level therapeutic strategy expands. In this context, the classification of potential therapeutics for the known and new targets against COVID-19 can be categorized according to different criteria. There are many categories of classification, which for example could be based on size differences including small molecular weight therapeutic molecules such as remdesivir and large molecules such as proteins (enzymes or antibodies, e.g., tocilizumab). Similarly, the classification of proposed therapeutic drugs could be based on targets associated with the SARS-CoV-2 viral life cycle. For example, in the early infective phase I, symptomatic treatment is considered; in the pulmonary phase II, treatment is based on monoclonal antibodies and antiviral agents aimed at inhibiting viral entry or replication in host cells; and the final hyperinflammatory phase III, drugs similar to tocilizumab and dexamethasone can be used (Table 1) [133]. Another approach is to classify drugs according to their target of specific symptoms and pathways, for example inflammation, 
redox stress and endothelial dysfunction, as well as related diagnostic marker changes (Table 1).

Many other categories and sub-categories of INDs could also be considered by either focusing on direct virustargeting drugs or on host-directed therapies, with the latter sub-divided into immunologic active pharmaceutics and host-cell targeting drugs [133, 134, 139]. For example, in the host-directed section there is an increased interest in the use of functional inhibitors of acid sphingomyelinase (FIASMA) including the antidepressant drugs fluoxetine and fluvoxamine, which with their role in sequestration of cholesterol in the endolysosomal compartment, involved in the virus entry side, have shown great effect in cell culture and in clinical trials against COVID-19 [140148]. Drug combination strategies of host-directed drugs such as the FIASMA fluoxetine and antiviral drugs such as remdesivir and its derivate GS-441524 have also been investigated against SARS-CoV-2 in vitro showing synergistic effects [149]. Potential synergistic or antagonistic effects against SARS-CoV-2 have also been suggested for other different drug combinations [150]. Encouraging developments have also been reported for INDs involved in the immunological active pharmaceutical section [139].

In the meantime, there is continuous evaluation and re-evaluation of new and already approved drugs respectively from the regulatory authorities, as well as hundreds of proposed INDs for old and newly identified targets [151]. In particular, several drugs have been recently approved by the regulatory authorities of several countries for certain categories of COVID-19 patients and some, e.g., baricitinib, molnupiravir and PF-07321332/ritonavir are soon expected to be available worldwide. In this context, the FDA recently issued an emergency use authorization (EUA) for baricitinib, an immune-modulating monoclonal antibody/Janus kinase (JAK) inhibitor, which was previously used for the treatment of rheumatoid arthritis [152]. Baricitinib (4 mg, orally, 4 times a day, up to 14 days) is used for COVID-19 patients requiring high-flow oxygen or noninvasive ventilation and for other patients on dexamethasone needing higher levels of respiratory support [151, 153]. Similarly, molnupiravir is another antiviral drug which was initially developed to treat influenza and also recently licensed only in the United Kingdom to prevent severe COVID-19 infection in patients [154, 155]. It is a pro-drug of a synthetic nucleoside and exerts its antiviral action through introduction of copying errors during viral RNA replication. Preliminary reports suggest that oral molnupiravir reduced the risk of hospitalization and death from COVID-19 by about 50\% for newly diagnosed, high-risk patients [156]. Another antiviral drug PF-07321332/ritonavir is expected to receive emergency use authorization (EUA) by the FDA and the regulatory authorities of other countries for newly diagnosed, high-risk COVID-19 patients by the end of 2021. Oral PF-07321332/ritonavir has been shown to reduce hospi- tal admissions and deaths by 80-90\% among patients with COVID-19 who are at high risk of severe illness [157]. PF-07321332 inhibits the activity of the SARS-CoV-2-3CL protease, an enzyme that the coronavirus needs to replicate. Co-administration with ritonavir decreases the metabolism of PF-07321332 and maintains its antiviral activity at higher levels [157].

New therapeutic approaches including multi-level drug targeting strategies appear to be increasing and are likely to increase the prospects of treatment of COVID-19 patients. Therapeutic approaches of increasing efficacy and decreasing toxicity prospects in COVID-19 patients such as the combination of antivirals, e.g., PF-07321332/ritonavir and molnupiravir, as well as other drugs are of great interest and need further investigation.

\section{Conclusions}

Greater efforts are needed to control the COVID19 pandemic and to reduce the associated high rate of mortality to acceptable levels. These efforts are hampered by insufficient health policies including the lack of worldwide vaccine programs, ineffective prevention measures, inadequate drug screening procedures for emergency medicines, financial inequality among countries etc.

Several drugs such as tocilizumab, remdesivir and dexamethasone are being used routinely against COVID19 causing reduction in the mortality rate. Many more approved drugs and nutraceuticals, as well as their combinations have the capability and can be screened and used for further reduction of the SARS-CoV-2 viral load and against the serious or fatal toxic side effects caused by the infection. Similarly, several other approved drugs can also be screened and used to reduce the mortality rate in different categories of COVID-19 patients with concomitant underlying conditions, who are more susceptible to SARS-CoV-2 and its side effects.

It is hoped that new approaches on prevention, vaccination and also the introduction of more approved drugs such as baricitinib, molnupiravir and PF07321332/ritonavir, with different targeting potential could be used to reduce mortality and curb the COVID-19 pandemic. In general, most of these drugs are expected to be effective against all the SARS-CoV-2 variants including the new Omicron (B.1.1.529) variant and also their associated COVID-19 complications. The multi-target drug strategies could result in better therapies for infected patients and the restoration of the good health for a better quality of life of all humans worldwide.

\section{Author contributions}

GJK designed, wrote and edited the manuscript. SF reviewed the clinical aspects of a COVID-19 clinic. CNK reviewed the clinical aspects of COVID-19 and coedited the manuscript. 


\section{Ethics approval and consent to participate}

Not applicable.

\section{Acknowledgment}

Not applicable.

\section{Funding}

This research received no external funding.

\section{Conflict of interest}

The authors declare no conflict of interest.

\section{References}

[1] WHO Coronavirus (COVID-19) Dashboard. Available at: http s.//covid19.who.int (Accessed: 4 November 2021).

[2] Burden of influenza - WHO/Europe. Available at: https://www. euro.who.intsinfluenzasseasonal-influenza (Accessed: 14 July 2021).

[3] Verma AA, Hora T, Jung HY, Fralick M, Malecki SL, LapointeShaw L, et al. Characteristics and outcomes of hospital admissions for COVID-19 and influenza in the Toronto area. Canadian Medical Association Journal. 2021; 193: E410-E418.

[4] Malaria - WHO | World Health Organization. Available at: ht tps://www.who.int>Newsroom>Factsheets>Detail (Accessed: 14 July 2021).

[5] Al-Aly Z, Xie Y, Bowe B. High-dimensional characterization of post-acute sequalae of COVID-19. Nature. 2021. (in press)

[6] Samidurai A, Das A. Cardiovascular Complications Associated with COVID-19 and Potential Therapeutic Strategies. International Journal of Molecular Sciences. 2020; 21: 6790.

[7] Zhang N, Xu X, Zhou L, Chen G, Li Y, Yin H, et al. Clinical characteristics and chest CT imaging features of critically ill COVID-19 patients. European Radiology. 2020; 30: 61516160.

[8] Won JH, Lee H. The Current Status of Drug Repositioning and Vaccine Developments for the COVID-19 Pandemic. International Journal of Molecular Sciences. 2020; 21: 9775.

[9] Olliaro P, Torreele E, Vaillant M. COVID-19 vaccine efficacy and effectiveness - the elephant (not) in the room. The Lancet Microbe. 2021. (in press)

[10] Amit S, Regev-Yochay G, Afek A, Kreiss Y, Leshem E. Early rate reductions of SARS-CoV-2 infection and COVID-19 in BNT162b2 vaccine recipients. The Lancet. 2021; 397: 875-877.

[11] Kontoghiorghe CN, Andreou N, Constantinou K, Kontoghiorghes GJ. World health dilemmas: Orphan and rare diseases, orphan drugs and orphan patients. World Journal of Methodology. 2014; 4: 163-188.

[12] Davies NG, Jarvis CI, Edmunds WJ, Jewell NP, Diaz-Ordaz K, Keogh RH. Increased mortality in community-tested cases of SARS-CoV-2 lineage B.1.1.7. Nature. 2021; 593: 270-274.

[13] Kupferschmidt K. Fast-spreading UK. virus variant raises alarms. Science. 2021; 371: 9-10.

[14] Voloch CM, da Silva Francisco R, Jr de Almeida L, Cardoso CC, Brustolini OJ, Gerber AL, et al. Covid19-UFRJ Workgroup, LNCC Workgroup. Genomic characterization of a novel SARSCoV-2 lineage from Rio de Janeiro. Brazilian Journal of Virology. 2021; 95: e00119-21.

[15] Tegally H, Wilkinson E, Giovanetti M, Iranzadeh A, Fonseca V, Giandhari J, et al. Detection of a SARS-CoV-2 variant of concern in South Africa. Nature. 2021; 592: 438-443.
[16] Nilgiriwala K, Mandal A, Patel G, Mestry T, Vaswani S, Shaikh A, et al. Genome Sequences of Five SARS-CoV-2 Variants from Mumbai, India, Obtained by Nanopore Sequencing. Microbiology Resource Announcements. 2021; 10: e00231-21.

[17] Terpos E, Trougakos IP, Gavriatopoulou M, Papassotiriou I, Sklirou AD, Ntanasis-Stathopoulos I, et al. Low Neutralizing Antibody Responses Against SARS-CoV-2 in Elderly Myeloma Patients After the First BNT162b2 Vaccine Dose. Blood. 2021; 137: 3674-3676.

[18] Herishanu Y, Avivi I, Aharon A, Shefer G, Levi S, Bronstein Y, et al. Efficacy of the BNT162b2 mRNA COVID-19 vaccine in patients with chronic lymphocytic leukemia. Blood. 2021; 137: 3165-3173.

[19] Haberman RH, Herati R, Simon D, Samanovic M, Blank $\mathrm{RB}$, Tuen $\mathrm{M}$, et al. Methotrexate hampers immunogenicity to BNT162b2 mRNA COVID-19 vaccine in immune-mediated inflammatory disease. Annals of the Rheumatoid Diseases. 2021. (in press)

[20] Long Q, Tang X, Shi Q, Li Q, Deng H, Yuan J, et al. Clinical and immunological assessment of asymptomatic SARS-CoV-2 infections. Nature Medicine. 2020; 26: 1200-1204.

[21] Wu F, Liu M, Wang A, Lu L, Wang Q, Gu C, et al. Evaluating the Association of Clinical Characteristics with Neutralizing Antibody Levels in Patients who have Recovered from Mild COVID-19 in Shanghai, China. JAMA Internal Medicine. 2020; 180: 1356

[22] Nasserie T, Hittle M, Goodman SN. Assessment of the Frequency and Variety of Persistent Symptoms among Patients with COVID-19. JAMA Network Open. 2021; 4: e2111417.

[23] Mao L, Jin H, Wang M, Hu Y, Chen S, He Q, et al. Neurologic Manifestations of Hospitalized Patients with Coronavirus Disease 2019 in Wuhan, China. JAMA Neurology. 2020; 77: 683.

[24] Chou SH, Beghi E, Helbok R, Moro E, Sampson J, Altamirano $\mathrm{V}$, et al. GCS-NeuroCOVID Consortium and ENERGY Consortium. Global Incidence of Neurological Manifestations Among Patients Hospitalized With COVID-19-A Report for the GCS-NeuroCOVID Consortium and the ENERGY Consortium. JAMA Network Open. 2021; 4: e2112131.

[25] Taquet M, Geddes JR, Husain M, Luciano S, Harrison PJ. 6month neurological and psychiatric outcomes in 236379 survivors of COVID-19: a retrospective cohort study using electronic health records. The Lancet Psychiatry. 2021; 8: 416-427.

[26] Kaštelan S, Sopta M, Radonjić M, Kaštelan U, Kasun B. Economic Crises as a Motive for Change in Health Care Systems a Historical Perspective with Reference to the COVID-19 Pandemic. Acta Medico-Historica Adriatica. 2021; 18: 355-374.

[27] Abay KA, Amare M, Tiberti L, Andam KS. COVID-19-Induced Disruptions of School Feeding Services Exacerbate Food Insecurity in Nigeria. The Journal of Nutrition. 2021; 151: 22452254.

[28] Kreutz R, Dobrowolski P, Prejbisz A, Algharably EAE, Bilo G, Creutzig F, et al. Lifestyle, psychological, socioeconomic and environmental factors and their impact on hypertension during the coronavirus disease 2019 pandemic. Journal of Hypertension. 2021; 39: 1077-1089.

[29] Parlapani E, Holeva V, Nikopoulou VA, Kaprinis S, Nouskas I, Diakogiannis I. A review on the COVID-19-related psychological impact on older adults: vulnerable or not? Aging Clinical and Experimental Research. 2021; 33: 1729-1743.

[30] Madewell ZJ, Yang Y, Longini IM, Halloran ME, Dean NE. Household Transmission of SARS-CoV-2. JAMA Network Open. 2020; 3: e2031756.

[31] Qin J, You C, Lin Q, Hu T, Yu S, Zhou X. Estimation of incubation period distribution of COVID-19 using disease onset forward time: a novel cross-sectional and forward follow-up study. Science Advances. 2020; 6: eabc1202.

[32] Muñiz-Diaz E, Llopis J, Parra, R, Roig I, Ferrer G, Grifols J, et al. Relationship between the ABO blood group and COVID-19 
susceptibility, severity and mortality in two cohorts of patients. Blood Transfusion. 2021; 19: 54-63.

[33] Golinelli D. On the association between the ABO blood group and COVID-19 susceptibility. Blood Transfusion. 2021; 19: 8990.

[34] Geriatric Medicine Research Collaborative, Covid Collaborative, Welch C. Age and frailty are independently associated with increased COVID-19 mortality and increased care needs in survivors: results of an international multi-centre study. Age Ageing. 2021; 50: 617-630.

[35] Lee SW, Ha EK, Yeniova A, Moon SY, Kim SY, Koh HY, et al. Severe clinical outcomes of COVID-19 associated with proton pump inhibitors: a nationwide cohort study with propensity score matching. Gut. 2021; 70: 76-84.

[36] Zacharioudakis IM, Prasad PJ, Zervou FN, Basu A, Inglima K, Weisenberg SA, et al. Association of SARS-CoV-2 Genomic Load with Outcomes in Patients with COVID-19. Annals of the American Thoracic Society. 2021; 18: 900-903.

[37] Pairo-Castineira E, Clohisey S, Klaric L, Bretherick AD, Rawlik K, Pasko D, et al. Genetic mechanisms of critical illness in COVID-19. Nature. 2021; 591: 92-98.

[38] Viner RM, Mytton OT, Bonell C, Melendez-Torres GJ, Ward J, Hudson L, et al. Susceptibility to SARS-CoV-2 Infection among Children and Adolescents Compared with Adults. JAMA Pediatrics. 2021; 175: 143.

[39] Wang G, Zhang Q, Zhao X, Dong H, Wu C, Wu F, et al. Low high-density lipoprotein level is correlated with the severity of COVID-19 patients: an observational study. Lipids in Health and Disease. 2020; 19: 204.

[40] Ravindra VM, Grandhi R, Delic A, Hohmann S, Shippey E, Tirschwell D, et al. Impact of COVID-19 on the hospitalization, treatment, and outcomes of intracerebral and subarachnoid hemorrhage in the United States. PLoS ONE. 2021; 16: e0248728.

[41] Peckham H, de Gruijter NM, Raine C, Radziszewska A, Ciurtin C, Wedderburn LR, et al. Male sex identified by global COVID19 meta-analysis as a risk factor for death and ITU admission. Nature Communications. 2020; 11: 6317.

[42] La Vignera, S, Cannarella R, Condorelli RA, Torre F, Aversa A, Calogero AE. Sex-Specific SARS-CoV-2 Mortality: Among Hormone-Modulated ACE2 Expression, Risk of Venous Thromboembolism and Hypovitaminosis D. International Journal of Molecular Sciences. 2020; 21: 2948.

[43] Zeberg H, Pääbo S. A genomic region associated with protection against severe COVID-19 is inherited from Neandertals. Proceedings of the National Academy of Sciences. 2021; 118: e2026309118.

[44] Cherrie M, Clemens T, Colandrea C, Feng Z, Webb DJ, Weller $\mathrm{RB}$, et al. Ultraviolet A Radiation and COVID-19 Deaths in the USA with replication studies in England and Italy. British Journal of Dermatology. 2021; 185: 363-370.

[45] Harmooshi NN, Shirbandi K, Rahim F. Environmental concern regarding the effect of humidity and temperature on 2019-nCoV survival: fact or fiction. Environmental Science and Pollution Research. 2020; 27: 36027-36036.

[46] Agrawal A. Dendritic Cell-Airway Epithelial Cell Cross-Talk Changes with Age and Contributes to Chronic Lung Inflammatory Diseases in the Elderly. International Journal of Molecular Sciences. 2017; 18: 1206.

[47] Agrawal A, Agrawal S, Gupta S. Role of Dendritic Cells in Inflammation and Loss of Tolerance in the Elderly. Frontiers in Immunology. 2017; 8: 896.

[48] Clark A, Jit M, Warren-Gash C, Guthrie B, Wang H, Mercer SW, et al. Centre for the Mathematical Modelling of Infectious Diseases COVID-19 working group. Global, regional, and national estimates of the population at increased risk of severe COVID19 due to underlying health conditions in 2020: a modelling study. The Lancet. Global Health. 2020; 8: e1003-e1017.

[49] Fried MW, Crawford JM, Mospan AR, Watkins SE, Munoz B, Zink RC, et al. Patient Characteristics and Outcomes of 11721
Patients with Coronavirus Disease 2019 (COVID-19) Hospitalized across the United States. Clinical Infectious Diseases. 2021; 72: e558-e565.

[50] Nithya G, Lamech TM, Arumugam V, Dineshkumar T, Gopalakrishnan N, Aiswarya D, et al. A clinical study on the changing dynamics of disease severity, management strategies and outcomes of COVID-19 in patients requiring haemodialysis. Journal of Nephrology. 2021; 34: 999-1006.

[51] Yates T, Zaccardi F, Islam N, Razieh C, Gillies CL, Lawson CA, et al. Obesity, Ethnicity, and Risk of Critical Care, Mechanical Ventilation, and Mortality in Patients Admitted to Hospital with COVID-19: Analysis of the ISARIC CCP-UK Cohort. Obesity. 2021; 29: 1223-1230.

[52] Huntley BJF, Mulder IA, Di Mascio D, Vintzileos WS Vintzileos AM, Berghella V, et al. Adverse Pregnancy Outcomes among Individuals with and without Severe Acute Respiratory Syndrome Coronavirus 2 (SARS-CoV-2). Obstetrics \& Gynecology. 2021; 137: 585-596.

[53] Carr AC, Rowe S. The Emerging Role of Vitamin C in the Prevention and Treatment of COVID-19. Nutrients. 2020; 12: 3286.

[54] Kontoghiorghes, GJ, Kolnagou A, Kontoghiorghe CN, Mourouzidis L, Timoshnikov VA, Polyakov NE. Trying to Solve the Puzzle of the Interaction of Ascorbic Acid and Iron: Redox, Chelation and Therapeutic Implications. Medicines. 2020; 7: 45.

[55] Xu Y, Baylink DJ, Chen C, Reeves ME, Xiao J, Lacy C, et al. The importance of vitamin d metabolism as a potential prophylactic, immunoregulatory and neuroprotective treatment for COVID19. Journal of Translational Medicine. 2020; 18: 322.

[56] Turrubiates-Hernández FJ, Sánchez-Zuno GA, GonzálezEstevez G, Hernández-Bello J, Macedo-Ojeda G, Muñoz-Valle JF. Potential immunomodulatory effects of vitamin $D$ in the prevention of severe coronavirus disease 2019: An ally for Latin America (Review). International Journal of Molecular Sciences. 2021; 47: 32.

[57] Lowe KE, Zein J, Hatipoglu U, Attaway A. Association of Smoking and Cumulative Pack-Year Exposure with COVID-19 Outcomes in the Cleveland Clinic COVID-19 Registry. JAMA Internal Medicine. 2021; 181: 709.

[58] Fischer EP, Fischer MC, Grass D, Henrion I, Warren WS, Westman E. Low-cost measurement of face mask efficacy for filtering expelled droplets during speech. Science Advances. 2020; 6 : eabd3083.

[59] Kratzel A, Todt D, V’kovski P, Steiner S, Gultom M, Thao TTN, et al. Inactivation of Severe Acute Respiratory Syndrome Coronavirus 2 by who-Recommended Hand Rub Formulations and Alcohols. Emerging Infectious Diseases. 2020; 26: 1592-1595.

[60] Leslie RA, Zhou SS, Macinga DR. Inactivation of SARS-CoV-2 by commercially available alcohol-based hand sanitizers. American Journal of Infection Control. 2021; 49: 401-402.

[61] Steed LL, Costello J, Lohia S, Jones T, Spannhake EW, Nguyen S. Reduction of nasal Staphylococcus aureus carriage in health care professionals by treatment with a nonantibiotic, alcoholbased nasal antiseptic. American Journal of Infection Control. 2014; 42: 841-846.

[62] Hou YJ, Okuda K, Edwards CE, Martinez DR, Asakura T, Dinnon $\mathrm{KH}$, et al. SARS-CoV-2 Reverse Genetics Reveals a Variable Infection Gradient in the Respiratory Tract. Cell. 2020; 182: 429-446.e14.

[63] de Oliveira PM, Mesquita LCC, Gkantonas S, Giusti A, Mastorakos E. Evolution of spray and aerosol from respiratory releases: theoretical estimates for insight on viral transmission. Proceedings of the Royal Society a: Mathematical, Physical and Engineering Sciences. 2021; 477: 20200584.

[64] Casale M, Rinaldi V, Sabatino L, Moffa A, Ciccozzi M. Could nasal irrigation and oral rinse reduce the risk for COVID-19 infection? International Journal of Immunopathology and Pharmacology. 2020; 34: 205873842094175.

[65] Cegolon L, Javanbakht M, Mastrangelo G. Nasal disinfection 
for the prevention and control of COVID-19: a scoping review on potential chemo-preventive agents. International Journal of Hygiene and Environmental Health. 2020; 230: 113605.

[66] Higgins TS, Wu AW, Illing EA, Sokoloski KJ, Weaver BA, Anthony BP, et al. Intranasal Antiviral Drug Delivery and Coronavirus Disease 2019 (COVID-19): a State of the Art Review. Otolaryngology-Head and Neck Surgery. 2020; 163: 682-694.

[67] Vidgren, Kublik. Nasal delivery systems and their effect on deposition and absorption. Advanced Drug Delivery Reviews. 2018; 29: 157-177.

[68] Türker S, Onur E, Ozer Y. Nasal route and drug delivery systems. Pharmacy World \& Science. 2004; 26: 137-142.

[69] Beitia M, Delgado D, Sánchez P, Vallejo de la Cueva A, Cugat JR, Sánchez M. Platelet Lysate Nebulization Protocol for the Treatment of COVID-19 and Its Sequels: Proof of Concept and Scientific Rationale. International Journal of Molecular Sciences. 2021; 22: 1856.

[70] Monk PD, Marsden RJ, Tear, VJ, Brookes J, Batten TN, Mankowski M, et al. Inhaled Interferon Beta COVID-19 Study Group. Safety and efficacy of inhaled nebulised interferon beta1a (SNG001) for treatment of SARS-CoV-2 infection: a randomised, double-blind, placebo-controlled, phase 2 trial. Lancet Respiratory Medicine. 2021; 9: 196-206.

[71] Tomazou M, Bourdakou MM, Minadakis G, Zachariou M, Oulas A, Karatzas E, et al. Multi-omics data integration and networkbased analysis drives a multiplex drug repurposing approach to a shortlist of candidate drugs against COVID-19. Briefings in Bioinformatics. 2021; bbab114.

[72] Janik E, Niemcewicz M, Podogrocki M, Saluk-Bijak J, Bijak M. Existing Drugs Considered as Promising in COVID-19 Therapy. International Journal of Molecular Sciences. 2021; 22: 5434.

[73] Nadeem MS, Zamzami MA, Choudhry H, Murtaza BN, Kazmi I, Ahmad H, et al. Origin, Potential Therapeutic Targets and Treatment for Coronavirus Disease (COVID-19). Pathogens. 2020; 9: 307.

[74] Trougakos IP, Stamatelopoulos K, Terpos E, Tsitsilonis OE, Aivalioti E, Paraskevis D, et al. Insights to SARS-CoV-2 life cycle, pathophysiology, and rationalized treatments that target COVID-19 clinical complications. Journal of Biomedical Science. 2021; 28: 9.

[75] Borba MGS, Val FFA, Sampaio VS, Alexandre MAA, Melo GC, Brito M, et al. Effect of High vs Low Doses of Chloroquine Diphosphate as Adjunctive Therapy for Patients Hospitalized with Severe Acute Respiratory Syndrome Coronavirus 2 (SARS-CoV-2) Infection. JAMA Network Open. 2020; 3: e208857.

[76] Farsalinos K, Eliopoulos E, Leonidas DD, Papadopoulos GE, Tzartos S, Poulas K. Nicotinic Cholinergic System and COVID19: In Silico Identification of an Interaction between SARSCoV-2 and Nicotinic Receptors with Potential Therapeutic Targeting Implications. International Journal of Molecular Sciences. 2020; 21: 5807.

[77] Convertino I, Tuccori M, Ferraro S, Valdiserra G, Cappello E, Focosi D, et al. Exploring pharmacological approaches for managing cytokine storm associated with pneumonia and acute respiratory distress syndrome in COVID-19 patients. Critical Care. 2020; 24: 331.

[78] Prete M, Favoino E, Catacchio G, Racanelli V, Perosa F. SARSCoV-2 Inflammatory Syndrome. Clinical Features and Rationale for Immunological Treatment. International Journal of Molecular Sciences. 2020; 21: 3377.

[79] Laguna-Goya R, Utrero-Rico A, Talayero P, Lasa-Lazaro M, Ramirez-Fernandez A, Naranjo L, et al. IL-6-based mortality risk model for hospitalized patients with COVID-19. Journal of Allergy and Clinical Immunology. 2020; 146: 799-807.e9.

[80] Kreidieh F, Temraz S. SARS-CoV-2 Infected Patient: from a Hematologist's Perspective. Mediterranean Journal of Hematology and Infectious Diseases. 2020; 12: e2020078.

[81] Bolondi G, Russo E, Gamberini E, Circelli A, Meca MCC, Brogi
E, et al. Iron metabolism and lymphocyte characterisation during COVID-19 infection in ICU patients: an observational cohort study. World Journal of Emergency Surgery. 2020; 15: 41.

[82] Huang I, Pranata R, Lim MA, Oehadian A, Alisjahbana B. Creactive protein, procalcitonin, D-dimer, and ferritin in severe coronavirus disease-2019: a meta-analysis. Therapeutic Advances in Respiratory Disease. 2020; 14: 175346662093717.

[83] Jin M, Tong Q. Rhabdomyolysis as Potential Late Complication Associated with COVID-19. Emerging Infectious Diseases. 2020; 26: 1618-1620.

[84] Pereira GJdS, Leão AHFF, Erustes AG, Morais IBdM, Vrechi TAdM, Zamarioli LdS, et al. Pharmacological Modulators of Autophagy as a Potential Strategy for the Treatment of COVID19. International Journal of Molecular Sciences. 2021; 22: 4067.

[85] Hetzel M, Ackermann M, Lachmann N. Beyond "Big Eaters": The Versatile Role of Alveolar Macrophages in Health and Disease. International Journal of Molecular Sciences. 2021; 22: 3308.

[86] COVID-19 Host Genetics Initiative. Mapping the human genetic architecture of COVID-19. Nature. 2021. (in press)

[87] Meizlish ML, Pine AB, Bishai JD, Goshua G, Nadelmann ER, Simonov M, et al. A neutrophil activation signature predicts critical illness and mortality in COVID-19. Blood Advances. 2021; 5: 1164-1177.

[88] Clemente V, D’Arcy P, Bazzaro M. Deubiquitinating Enzymes in Coronaviruses and Possible Therapeutic Opportunities for COVID-19. International Journal of Molecular Sciences. 2020; 21: 3492.

[89] Terracciano R, Preianò M, Fregola A, Pelaia C, Montalcini T, Savino R. Mapping the SARS-CoV-2-Host Protein-Protein Interactome by Affinity Purification Mass Spectrometry and Proximity-Dependent Biotin Labeling: A Rational and Straightforward Route to Discover Host-Directed Anti-SARS-CoV2 Therapeutics. International Journal of Molecular Sciences. 2021; 22: 532.

[90] Homolak J, Kodvanj I. Widely available lysosome targeting agents should be considered as potential therapy for COVID19. International Journal of Antimicrobial Agents. 2020; 56: 106044.

[91] Asha K, Kumar P, Sanicas M, Meseko CA, Khanna M, Kumar B. Advancements in Nucleic Acid Based Therapeutics against Respiratory Viral Infections. Journal of Clinical Medicine. 2018; 8: 6 .

[92] Huang J, Song W, Huang H, Sun Q. Pharmacological Therapeutics Targeting RNA-Dependent RNA Polymerase, Proteinase and Spike Protein: From Mechanistic Studies to Clinical Trials for COVID-19. Journal of Clinical Medicine. 2020; 9: 1131.

[93] Calligari P, Bobone S, Ricci G, Bocedi A. Molecular Investigation of SARS-CoV-2 Proteins and Their Interactions with Antiviral Drugs. Viruses. 2020; 12: 445.

[94] Gragueb-Chatti I, Lopez A, Hamidi D, Guervilly C, Loundou A, Daviet F, et al. Impact of dexamethasone on the incidence of ventilator-associated pneumonia and blood stream infections in COVID-19 patients requiring invasive mechanical ventilation: a multicenter retrospective study. Annals of Intensive Care. 2021; 11: 87.

[95] Pinzón MA, Ortiz S, Holguín H, Betancur JF, Cardona Arango $\mathrm{D}$, Laniado $\mathrm{H}$, et al. Dexamethasone vs methylprednisolone high dose for COVID-19 pneumonia. PLoS ONE. 2021; 16: e0252057.

[96] Pelaia C, Calabrese C, Garofalo E, Bruni A, Vatrella A, Pelaia G. Therapeutic Role of Tocilizumab in SARS-CoV-2-Induced Cytokine Storm: Rationale and Current Evidence. International Journal of Molecular Sciences. 2021; 22: 3059.

[97] Selvaraj V, Khan MS, Bavishi C, Dapaah-Afriyie K, Finn A, Lal A, et al. Tocilizumab in Hospitalized Patients with COVID-19: A Meta Analysis of Randomized Controlled Trials. Lung. 2021; 199: 239-248

[98] Fernando SM, Rochwerg B. In COVID-19, tocilizumab reduces 
all-cause mortality at $28 \mathrm{~d}$. Annals of Internal Medicine. 2021; 174: JC63.

[99] Humeniuk R, Mathias A, Cao H, Osinusi A, Shen G, Chng E, et al. Safety, Tolerability, and Pharmacokinetics of Remdesivir, An Antiviral for Treatment of COVID-19, in Healthy Subjects. Clinical and Translational Science. 2020; 13: 896-906.

[100] Grein J, Ohmagari N, Shin D, Diaz G, Asperges E, Castagna A, et al. Compassionate Use of Remdesivir for Patients with Severe COVID-19. New England Journal of Medicine. 2020; 382: 2327-2336.

[101] Goldman DL, Aldrich ML, Hagmann SHF, Bamford A, Camacho-Gonzalez A, Lapadula G, et al. Compassionate Use of Remdesivir in Children with Severe COVID-19. Pediatrics. 2021; 147: e2020047803.

[102] Rentsch CT, Beckman JA, Tomlinson L, Gellad WF, Alcorn C, Kidwai-Khan F, et al. Early initiation of prophylactic anticoagulation for prevention of coronavirus disease 2019 mortality in patients admitted to hospital in the United States: cohort study. British Medical Journal. 2021; 372: n311.

[103] Braz-de-Melo HA, Faria SS, Pasquarelli-do-Nascimento G, Santos IO, Kobinger GP, Magalhães KG. The Use of the Anticoagulant Heparin and Corticosteroid Dexamethasone as Prominent Treatments for COVID-19. Frontiers in Medicine. 2021; 8: 615333.

[104] Temesgen Z, Burger CD, Baker J, Polk C, Libertin C, Kelley $\mathrm{C}$, et al. Lenzilumab efficacy and safety in newly hospitalized covid-19 subjects: results from the live-air phase 3 randomized double-blind placebo-controlled trial. MedRxiv. 2021. (in press)

[105] Ledford H. COVID antibody treatments show promise for preventing severe disease. Nature. 2021; 591: 513-514.

[106] Loffredo L, Violi F. COVID-19 and cardiovascular injury: a role for oxidative stress and antioxidant treatment? International Journal of Cardiology. 2020; 312: 136.

[107] Metnitz PG, Bartens C, Fischer M, Fridrich P, Steltzer H, Druml W. Antioxidant status in patients with acute respiratory distress syndrome. Intensive Care Medicine. 1999; 25: 180-185.

[108] Rahimi A, Samimagham HR, Azad MH, Hooshyar D, Arabi M, KazemiJahromi M. The efficacy of $N$-Acetylcysteine in severe COVID-19 patients: a structured summary of a study protocol for a randomised controlled trial. Trials. 2021; 22: 271.

[109] Sharafkhah M, Abdolrazaghnejad A, Zarinfar N, Mohammadbeigi A, Massoudifar A, Abaszadeh S. Safety and efficacy of $\mathrm{N}$-acetyl-cysteine for prophylaxis of ventilator-associated pneumonia: a randomized, double blind, placebo-controlled clinical trial. Medical Gas Research. 2018; 8: 19-23.

[110] Zhang Y, Ding S, Li C, Wang Y, Chen Z, Wang Z. Effects of $N$ acetylcysteine treatment in acute respiratory distress syndrome: a meta-analysis. Experimental and Therapeutic Medicine. 2017; 14: 2863-2868.

[111] Kontoghiorghes GJ, Kontoghiorghe CN. Prospects for the introduction of targeted antioxidant drugs for the prevention and treatment of diseases related to free radical pathology. Expert Opinion on Investigational Drugs. 2019; 28: 593-603.

[112] Kontoghiorghe CN, Kolnagou A, Kontoghiorghes GJ. Antioxidant targeting by deferiprone in diseases related to oxidative damage. Frontiers in Bioscience. 2014; 19: 862-885.

[113] Tanner MA, Galanello R, Dessi C, Smith GC, Westwood MA, Agus A, et al. A randomized, placebo-controlled, double-blind trial of the effect of combined therapy with deferoxamine and deferiprone on myocardial iron in thalassemia major using cardiovascular magnetic resonance. Circulation. 2007; 115: 18761884.

[114] Maggio A, Vitrano A, Lucania G, Capra M, Cuccia L, Gagliardotto F, et al. Long-term use of deferiprone significantly enhances left-ventricular ejection function in thalassemia major patients. American Journal of Hematology. 2012; 87: 732-733.

[115] Matthews AJ, Vercellotti GM, Menchaca HJ, Bloch PH, Michalek VN, Marker PH, et al. Iron and atherosclerosis: inhibition by the iron chelator deferiprone (L1). The Journal of
Surgical Research. 1997; 73: 35-40.

[116] Chan S, Lian Q, Chen M, Jiang D, Ho JTK, Cheung Y, et al Deferiprone inhibits iron overload-induced tissue factor bearing endothelial microparticle generation by inhibition oxidative stress induced mitochondrial injury, and apoptosis. Toxicology and Applied Pharmacology. 2018; 338: 148-158.

[117] Liu W, Zhang S, Nekhai S, Liu S. Depriving Iron Supply to the Virus Represents a Promising Adjuvant Therapeutic against Viral Survival. Current Clinical Microbiology Reports. 2020; 7: 13-19.

[118] Lemaitre F, Solas C, Grégoire M, Lagarce L, Elens L, Polard E, et al. Potential drug-drug interactions associated with drugs currently proposed for COVID-19 treatment in patients receiving other treatments. Fundamental \& Clinical Pharmacology. 2020; 34: $530-547$.

[119] Kumar D, Trivedi N. Disease-drug and drug-drug interaction in COVID-19: Risk and assessment. Biomedicine \& Pharmacotherapy. 2021; 139: 111642

[120] Massarweh A, Eliakim-Raz N, Stemmer A, Levy-Barda A, Yust-Katz S, Zer A, et al. Evaluation of Seropositivity Following BNT162b2 Messenger RNA Vaccination for SARS-CoV-2 in Patients Undergoing Treatment for Cancer. JAMA Oncology. 2021; 7: 1133.

[121] Kennedy NA, Lin S, Goodhand JR, Chanchlani N, Hamilton B, Bewshea C, et al. Contributors to the CLARITY IBD study. Infliximab is associated with attenuated immunogenicity to BNT162b2 and ChAdOx1 nCoV-19 SARS-CoV-2 vaccines in patients with IBD. Gut. 2021. (in press)

[122] Kontoghiorghes GJ. Differences between the European Union and United States of America in Drug Regulatory Affairs Affect Global Patient Safety Standards and Public Health Awareness: The Case of Deferasirox and Other Iron Chelating Drugs. Medicines. 2021; 8: 36.

[123] Kontoghiorghes GJ, Kolnagou A, Fetta S, Kontoghiorghe CN. Conventional and Unconventional Approaches for Innovative Drug Treatments in COVID-19: Looking Outside of Plato's Cave. International Journal of Molecular Sciences. 2021; 22: 7208.

[124] Kontoghiorghes GJ, Kleanthous M, Kontoghiorghe CN. The History of Deferiprone (L1) and the Paradigm of the Complete Treatment of Iron Overload in Thalassaemia. Mediterranean Journal of Hematology and Infectious Diseases. 2020 12: e2020011.

[125] Kontoghiorghes GJ. Do we need more iron-chelating drugs? Lancet. 2003; 362: 495-496.

[126] Kontoghiorghes GJ, Kolnagou A, Demetriou T, Neocleous M, Kontoghiorghe CN. New Era in the Treatment of Iron Deficiency Anaemia Using Trimaltol Iron and Other Lipophilic Iron Chelator Complexes: Historical Perspectives of Discovery and Future Applications. International Journal of Molecular Sciences. 2021; 22: 5546.

[127] Kontoghiorghes GJ, Goddard JG, Bartlett AN, Sheppard L. Pharmacokinetic studies in humans with the oral iron chelator 1,2-dimethyl-3-hydroxypyrid-4-one. Clinical Pharmacology and Therapeutics. 1990; 48: 255-261.

[128] Das K, Pingali MS, Paital B, Panda F, Pati SG, Singh A, et al. A detailed review of the outbreak of COVID-19. Frontiers in Bioscience. 2021; 26: 149-170.

[129] Rochette L, Ghibu S. Mechanics Insights of Alpha-Lipoic Acid against Cardiovascular Diseases during COVID-19 Infection. International Journal of Molecular Sciences. 2021; 22: 7979.

[130] Planas D, Veyer D, Baidaliuk A, Staropoli I, GuivelBenhassine F, Rajah MM, et al. Reduced sensitivity of SARSCoV-2 variant Delta to antibody neutralization. Nature. 2021; 596: 276-280.

[131] COVID-19 Host Genetics Initiative. Mapping the human genetic architecture of COVID-19. Nature. 2021. (in press)

[132] Sterr CM, Nickel IL, Stranzinger C, Nonnenmacher-Winter CI, Günther F. Medical face masks offer self-protection against 
aerosols: An evaluation using a practical in vitro approach on a dummy head. PLoS ONE. 2021; 16: e0248099.

[133] Mouffak S, Shubbar Q, Saleh E, El-Awady R. Recent advances in management of COVID-19: a review. Biomedicine \& Pharmacotherapy. 2021; 143: 112107.

[134] Srivastava K, Singh MK. Drug repurposing in COVID-19: a review with past, present and future. Metabolism Open. 2021; 12: 100121.

[135] Giannis D, Ziogas IA, Gianni P. Coagulation disorders in coronavirus infected patients: COVID-19, SARS-CoV-1, MERS$\mathrm{CoV}$ and lessons from the past. Journal of Clinical Virology. 2020; 127: 104362.

[136] Sobreira da Silva MJ, Serpa Osorio-de-Castro CG, Paes RD, Negrete CL, Eugênio E, Moraes EL, et al. Potential interactions between antineoplastic agents and medicines used to treat COVID-19. Journal of Oncology Pharmacy Practice. 2021. (in press)

[137] Shafiekhani M, Dehghani A, Shahisavandi M, Nabavizadeh SA, Kabiri M, Hassani AH, et al. Pharmacotherapeutic approach toward urological medications and vaccination during COVID19: a narrative review. Therapeutic Advances in Urology. 2021; 13: 175628722110467.

[138] Shen Y, Cheng C, Zheng X, Jin Y, Duan G, Chen M, Chen S. Elevated Procalcitonin Is Positively Associated with the Severity of COVID-19: A Meta-Analysis Based on 10 Cohort Studies. Medicina. 2021; 57: 594.

[139] Burrage DR, Koushesh S, Sofat N. Immunomodulatory Drugs in the Management of SARS-CoV-2. Frontiers in immunology. 2020; 11: 1844

[140] Schloer S, Brunotte L, Goretzko J, Mecate-Zambrano A, Korthals N, Gerke V, et al. Targeting the endolysosomal hostSARS-CoV-2 interface by clinically licensed functional inhibitors of acid sphingomyelinase (FIASMA) including the antidepressant fluoxetine. Emerging Microbes \& Infections. 2020; 9: 2245-2255.

[141] Hoertel N, Sánchez-Rico M, Cougoule C, Gulbins E, Kornhuber J, Carpinteiro A, et al. Repurposing antidepressants inhibiting the sphingomyelinase acid/ceramide system against COVID-19: current evidence and potential mechanisms. Molecular Psychiatry. 2021; 1-2.

[142] Lenze EJ, Mattar C, Zorumski CF, Stevens A, Schweiger J, Nicol GE, et al. Fluvoxamine vs Placebo and Clinical Deterioration in Outpatients with Symptomatic COVID-19. The Journal of the American Medical Association. 2020; 324: 2292.

[143] Loas G, Le Corre P. Update on Functional Inhibitors of Acid Sphingomyelinase (FIASMAs) in SARS-CoV-2 Infection. Pharmaceuticals. 2021; 14: 691.

[144] Le Corre P, Loas G. Repurposing functional inhibitors of acid sphingomyelinase (fiasmas): an opportunity against SARSCoV-2 infection? Journal of Clinical Pharmacy and Therapeutics. 2021; 46: 1213-1219.

[145] Hoertel N, Sánchez-Rico M, Gulbins E, Kornhuber J, Carpinteiro A, Lenze EJ, et al. Association Between FIASMAs and Reduced Risk of Intubation or Death in Individuals Hospitalized for Severe COVID-19: An Observational Multicenter Study. Clinical Pharmacology and Therapeutics. 2021; 110: 1498-1511.

[146] Alketbi EH, Hamdy R, El-Kabalawy A, Juric V, Pignitter M, Mosa K, et al. Lipid-based therapies against SARS-CoV-2 infection. Reviews in Medical Virology. 2021; 31: 1-13.

[147] Abu-Farha M, Thanaraj TA, Qaddoumi MG, Hashem A, Abubaker J, Al-Mulla F. The Role of Lipid Metabolism in COVID-19 Virus Infection and as a Drug Target. International Journal of Molecular Sciences. 2020; 21: 3544.

[148] Kornhuber J, Hoertel N, Gulbins E. The acid sphingomyelinase/ceramide system in COVID-19. Molecular Psychiatry. 2021; $1-8$.
[149] Schloer S, Brunotte L, Mecate-Zambrano A, Zheng S, Tang J, Ludwig S, et al. Drug synergy of combinatory treatment with remdesivir and the repurposed drugs fluoxetine and itraconazole effectively impairs SARS-CoV-2 infection in vitro. British Journal of Pharmacology. 2021; 178: 2339-2350.

[150] Bobrowski T, Chen L, Eastman RT, Itkin Z, Shinn P, Chen CZ, et al. Synergistic and Antagonistic Drug Combinations against SARS-CoV-2. Molecular Therapy. 2021; 29: 873-885.

[151] Kim AY, Gandhi RT. COVID-19: Management in hospitalized adults. 2021. Available at: https://www.uptodate.com/content s/COVID-19-management-in-hospitalized-adults?search=und efined\&source=covid19_landing\&usage_type=main_section (Accessed: 8 November 2021).

[152] Taylor PC, Takeuchi T, Burmester GR, Durez P, Smolen JS, Deberdt W, et al. Safety of baricitinib for the treatment of rheumatoid arthritis over a median of 4.6 and up to 9.3 years of treatment: final results from long-term extension study and integrated database. Annals of the Rheumatic Diseases. 2021. (in press)

[153] Bassetti M, Giacobbe DR, Bruzzi P, Barisione E, Centanni S, Castaldo N, et al. Clinical Management of Adult Patients with COVID-19 outside Intensive Care Units: Guidelines from the Italian Society of Anti-Infective Therapy (SITA) and the Italian Society of Pulmonology (SIP). Infectious Diseases and Therapy. 2021; 10: 1837-1885.

[154] Cox RM, Wolf JD, Plemper RK. Therapeutically administered ribonucleoside analogue MK-4482/EIDD-2801 blocks SARSCoV-2 transmission in ferrets. Nature Microbiology. 2021; 6: 11-18.

[155] Mahase E. COVID-19: UK becomes first country to authorise antiviral molnupiravir. British Medical Journal. 2021; 375: n2697.

[156] Mahase E. COVID-19: Molnupiravir reduces risk of hospital admission or death by $50 \%$ in patients at risk, MSD reports. British Medical Journal. 2021; 375: n2422.

[157] Mahase E. COVID-19: Pfizer's paxlovid is 89\% effective in patients at risk of serious illness, company reports British Medical Journal. 2021; 375: n2713

Abbreviations: ACE2, angiotensin converting enzyme 2; ARDS, acute respiratory distress syndrome; EMA, European medicines agency; FDA, food and drug administration; FIASMA, inhibitors of acid sphingomyelinase; GM-CSF, granulocyte-macrophage colony-stimulating factor; COVID-19, coronavirus disease 2019; IL, interleukin, e.g., IL-1, IL-6, IL-8; iv, intravenous; IND, investigational new drugs; LDH, lactate dehydrogenase; LMWH, low molecular weight heparin; MERS-CoV, Middle East Respiratory Syndrome coronavirus; p.o., oral administration; QALY, quality-adjusted life years; SARS-CoV-1, severe acute respiratory syndrome coronavirus 1; SARS-CoV-2, severe acute respiratory syndrome coronavirus 2; sc, subcutaneous; TMPRSS2, transmembrane protease serine 2; WHO, world health organization.

Keywords: COVID-19; SARS-CoV-2; Drugs; Baricitinib; Molnupiravir; PF-07321332/ritonavir; Vaccines; Drug targeting; Health strategies

Send correspondence to: George J. Kontoghiorghes, Postgraduate Research Institute of Science, Technology, Environment and Medicine, 3021 Limassol, Cyprus, E-mail: kontoghiorghes.g.j@pri.ac.cy 